\title{
What Kind of Community Development System Can Effectively Support Citywide Philanthropic Efforts to Promote Community Well-Being?
}

\author{
Joongsub Kim ${ }^{1}$
}

Received: 1 October 2020 / Accepted: 28 June 2021 / Published online: 13 July 2021

(c) The Author(s), under exclusive licence to Springer Nature Switzerland AG 2021

\begin{abstract}
How can the efforts of philanthropic agencies be better supported to promote citywide community well-being? To address this question, this article uses a citywide, engagement-driven initiative led by local practitioners that took place in Detroit between 2016 and 2019. This article is based on the initiative's two main outcomes, namely the identification of seven elements of an effective community development system and a vitality framework designed to measure community progress and success. The author of this article conducted participant observation, interviews, and a literature review, as well as site visits to, and case studies on, four best-practice cities, and then used the outcomes to validate the results of the initiative. Informed by the outcomes of the initiative and the research, the article suggests how best to utilize the seven community development system elements and the vitality success framework effectively to support philanthropy that promotes community well-being. This article focuses on theory-building in Detroit and calls for empirical research to further validate the findings. The article provides useful insights into the benefits of community-based research and citywide engagement as essential components of an effective community development system that can coordinate philanthropic practice more effectively to promote community well-being.
\end{abstract}

Keywords Community engagement - Community development · System elements · Vitality $\cdot$ Community well-being 


\section{Introduction}

This article focuses on philanthropic institutions in Detroit. A philanthropic institution is described as an agency that makes gifts to organizations that engage in community development. Such institutions include charitable foundations and financial institutions (e.g. banks). Organizations that participate in community development include community development corporations (CDCs), community development organizations (CDOs), and grassroots organizations or other nonprofit entities (e.g. service providers for community development groups, municipal departments, universities, faith-based institutions, and the like). Philanthropy generally has a positive impact on community well-being. It is, however, debatable whether philanthropy has succeeded overall in promoting well-being citywide (Braverman et al., 2004; Prilleltensky \& Prilleltensky, 2007). Most philanthropic success lies in micro-level projects or programs (e.g. funding support for a community garden), whereas the impact of philanthropic efforts at the macro level (e.g. citywide success) is difficult to measure (Martinez-Cosio \& Bussell, 2013). This in part reflects the typical focus of a philanthropic agency on a particular type of project in a specific target area, whereas other agencies may choose multiple areas with distinct funding targets. Even though philanthropic institutions might like to work together to achieve a positive citywide impact, they face a major barrier, namely the lack of an effective community development system that covers an entire city, especially in cities like Detroit with large low-income populations (Leventhal et al., 2007).

What does it take for a city to help philanthropists promote community wellbeing on a citywide scale? What conditions need to be met so that philanthropic institutions can coordinate their funding allocations and administration more effectively, thereby increasing the level of community well-being throughout an entire city? These are among the questions this article addresses.

This study engages primarily in theory-building supplemented by a literature review, interviews, site visits to, and precedent studies about, community development systems in four major American cities: Cleveland, Indianapolis, Boston, and Philadelphia. The study focuses in particular on a citywide civic engagement initiative in Detroit (the author uses the terms "the citywide engagement initiative," "the engagement initiative," "the initiative," and "the engagement" interchangeably in this article). The purpose of the research is twofold: to propose seven key elements of an effective community development system and to demonstrate that those elements can effectively support philanthropic endeavors in efforts to promote community well-being citywide. It is the intent of this article to show that the research results will benefit Detroit.

To address the abovementioned questions and purposes, we review the interdisciplinary literature on philanthropy, community well-being, and community development. Building on achievements in the literature, we identify areas that need more attention, such as coordination between philanthropic institutions. Next, we discuss challenges (e.g. insufficient coordination and the absence of a community development system) facing philanthropy in promoting community 
well-being across Detroit. Next we explain Detroit's citywide engagement initiative process and its key outcomes - the seven elements of a community development system and the vitality framework concept (whose primary dimension is community well-being) as a common narrative for community development in Detroit. Finally, we discuss how the seven elements can help philanthropic institutions coordinate their efforts more effectively to promote citywide community well-being, and we highlight lessons learned from our study. We discuss the study approaches and data collection methods in greater detail in the Method section (see Fig. 1).

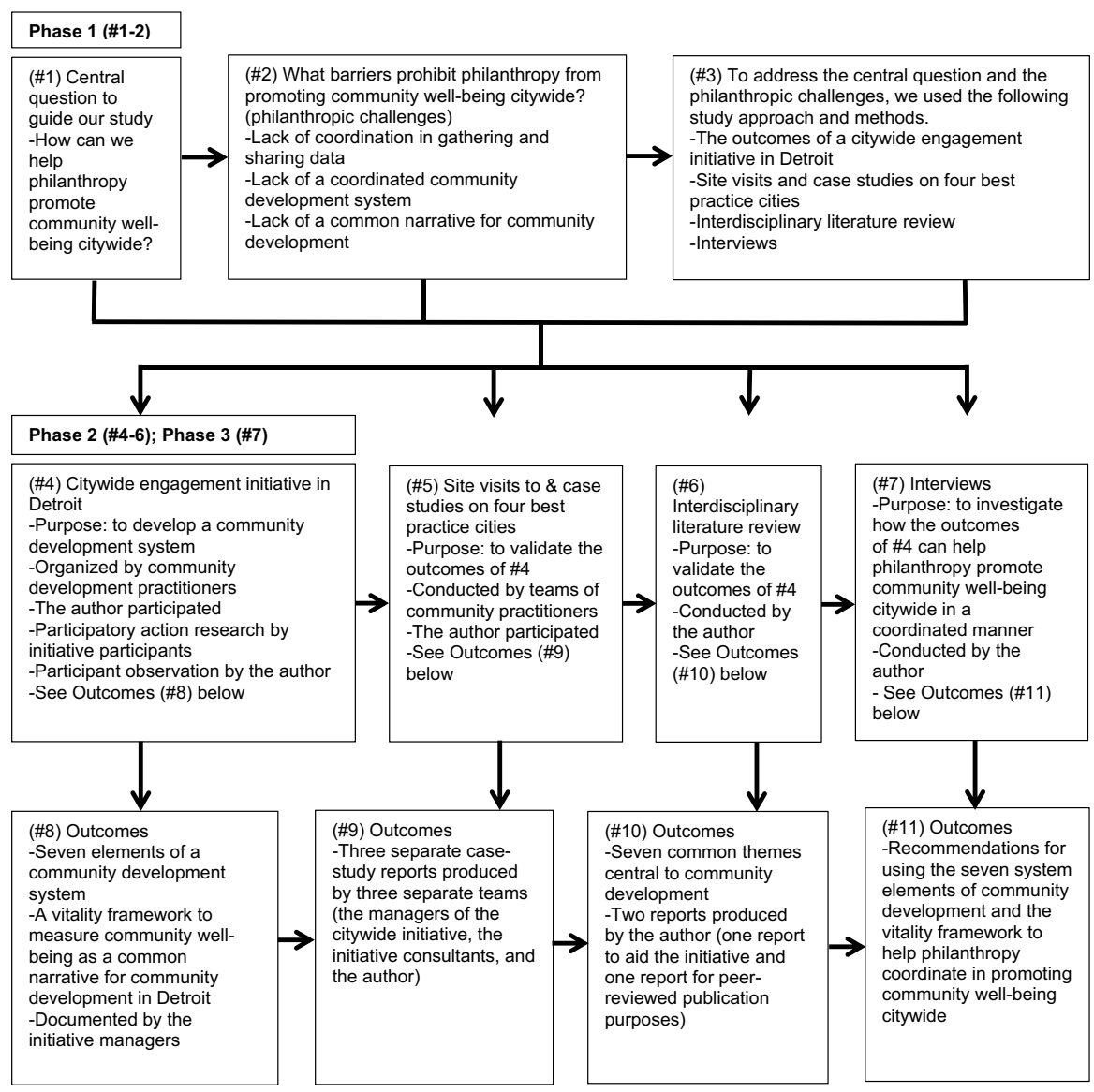

Fig. 1 A diagram illustrating the overall study approach 


\section{Literature on Community Well-Being, Community Development, and Philanthropy}

A positive and significant relationship exists between key dimensions of community well-being (economic empowerment; social, environment, political, and health services; and facilities) and community well-being (Edwards, 2011; Rela et al., 2020). Various indicators that are used to measure community well-being along those dimensions exist in the literature (Rela et al., 2020). The dimensions that are relevant to our case study in Detroit include (with indicators in parentheses): the Economic Empowerment Dimension (e.g. income sufficiency) (Lee \& Kim, 2015); the Social Dimension (e.g. community spirit and cohesion, trust, participation) (Dolan, 2008; Kravetz, 2017; Sirgy et al., 2010); the Environmental Dimension (e.g. environmental quality and sustainability) (Diener et al., 2009; Kottke et al., 2017; Walton et al., 2014); the Political Dimension (e.g. democratic and engaged communities) (Matarrita-Cascante \& Brennan, 2012; McCrea et al., 2014; Tov \& Diener, 2009); the Health Dimension (e.g. physical and psychological health) (Kottke et al., 2017; Palmer, 2020); and the Services and Facilities Dimension (e.g. sustainable built and natural environment) (Walton et al., 2014). To address all those dimensions would require coordination among various entities (e.g. philanthropists, CDOs) to enable them to establish strategies for creating the community their residents want to live in; cities need in particular strategies that are based in multiple sectors or cross-disciplinary collaboration to address the complex task of shaping places in fragmented societies (Bradshaw, 2000; Healey, 2003).

Community development in general seeks to address the well-being of communities (Harrow \& Jung, 2016), and a significant relationship exists between community well-being and community development (Diener et al., 2009; Diener et al., 2009; Frey, 2008; Lee \& Kim, 2015). Yet it is difficult for any single community development project to address all aspects of community well-being. Thus it is typical that each development project in every community has a unique focus (Jones, 2019). In the case of community development that aims at promoting solidarity and agency (Bhattacharyya, 2004; Ledwith, 2020), "social support," "social justice," and "social capital" are regarded as the trilogy of community development imperatives (Dolan, 2008). The process involved in such development would entail "organization, facilitation, and action which allows people to establish ways to create the community they want to reside in" (Matarrita-Cascante \& Brennan, 2012, p. 297). This type of community development is geared to addressing the social and political (and also health) dimensions of community well-being (Kravetz, 2017; Ledwith, 2020), although a variety of community development projects also incorporate some elements of economic, environmental, services, and facilities dimensions of community well-being (Wilson, 2019).

On the other hand, it is important to consider who leads community development, because development leaders have an impact on the direction, scope, focus, and process of community engagement as a means of promoting community wellbeing as an outcome of development. To further explore that aspect, we focus 
on three types of community development that Matarrita-Cascante and Brennan (2012, p. 289) suggest: "imposed," "directed," and "self-help" community development. "Imposed" community development occurs when governments or private developers generate improvements to make life or community living conditions better but without community involvement; "directed" community development applies where functional and structural improvements occur via governmental and/or non-governmental organizations, through community exchange, providing residents with some information and voice; finally, "self-help" community development applies where community benefits are associational, with high levels of capacity-building and with residents directing change (Harrow \& Jung, 2016; Matarrita-Cascante \& Brennan, 2012). The well-being of a geographically bounded community is, however, central to community development, whether community development is "imposed," "directed," or "self-help"-based, and whether community well-being is defined narrowly (e.g. limiting the dimensions to be addressed) or more broadly (e.g. addressing all or a majority of the dimensions) (Foell \& Pitzer, 2020).

Conceptualizations of philanthropy are similarly wide-ranging. Philanthropic resource provision ranges from "top-down" forms-such as philanthropic gift-giving, which relies on significant wealth, inter-generational transmission, and control-to "ground-up" gift-giving through local communal actions, producing mutual support (Harrow \& Jung, 2016; Reich, 2014). Despite such variability, philanthropic institutions prefer place-based resource provision (Glückler \& Ries, 2012). Placebased philanthropy draws on geographical, rather than virtual or relational, communities, building on the concept that geographical proximity is seen to benefit both donors and recipients. Glückler and Ries contend that, in place-based philanthropy, philanthropic access is a matter not only of proximity but also of networking: "being there" and "being connected" with community development players living or working in their specific locale where community development occurs (2012, p. 525).

Based on lessons drawn from summarizing the literature, this article notes in particular that, while community well-being is impacted by philanthropy and community development in a significant way, the context of a geographic location (e.g. a neighborhood, a city) plays an important role in defining the focus of and addressing community well-being. At the same time, determining how to coordinate the efforts of CDOs and philanthropic institutions in an equitable and collaborative manner deserves attention. To that end, scholars increasingly show interest in the interdisciplinary literature that connects those three fields and other areas such as public health, planning, and healthy community design to enhance community well-being more effectively (Forsyth, 2020; Kim, 2020a).

Informed by the interdisciplinary literature, further research on coordination between various philanthropic institutions in promoting community well-being citywide is needed. This is important, especially when several philanthropic institutions invest in the same geographical community, or when multiple institutions address the same issue across an entire city like Detroit. While the literature illuminates useful connections between community well-being and community development (Lee et al., 2014; Rela et al., 2020), more research is needed to gauge the impact of a bottom-up approach to a community development system on community well-being 
and to understand how such an approach can help philanthropic institutions address citywide community well-being. Using the results of our case study based in Detroit, this article investigates how the efforts of philanthropic institutions can be better coordinated and better aligned with a citywide community development system to promote community well-being more effectively. In addressing these issues, this article fills the gap and contributes to the interdisciplinary literature.

\section{Method}

What challenges do philanthropists face when they endeavor to promote community well-being in Detroit? How can their efforts be more effective? To address these issues, we carried out this research in three phases that were central to our overall approach (see Table 1).

\section{Phases}

\section{Phase 1}

In the first phase we sought to understand the challenges that philanthropists face in practice with regard to community development and well-being in Detroit. This discussion is based on the results of the author's participant-observations of philanthropists and other players who participated in the abovementioned citywide engagement initiative (see Phase 2 for additional details), supplemented by the results of interviews, a literature review, and case studies on and site visits to four best-practice cities. These results will be discussed in the Results section.

\section{Phase 2}

In the second phase we sought to understand how seven elements of a community development system for Detroit were identified by the abovementioned initiative. Here we describe the engagement process that produced the seven system elements. The vitality success framework concept was developed along with the seven system elements. A key dimension of the framework is community well-being. Next, we explain how the seven community development elements are supported by the results of the case studies and findings from the pertinent literature.

Some 200 local practitioners, including public officials, educators, and other key stakeholders in community development representing various sectors, participated in the citywide engagement initiative. Participating groups included CDCs, CDOs, financial institutions (e.g. philanthropic institutions), municipal departments, higher-learning institutions, civic groups, and other non-profit organizations. This engagement process was initiated in 2016 by several organizations that are deeply interested in community development. Although these organizations started this initiative, many in the city recognize that all 200 participants own the initiative and the engagement process. The primary purpose of this engagement was to develop 


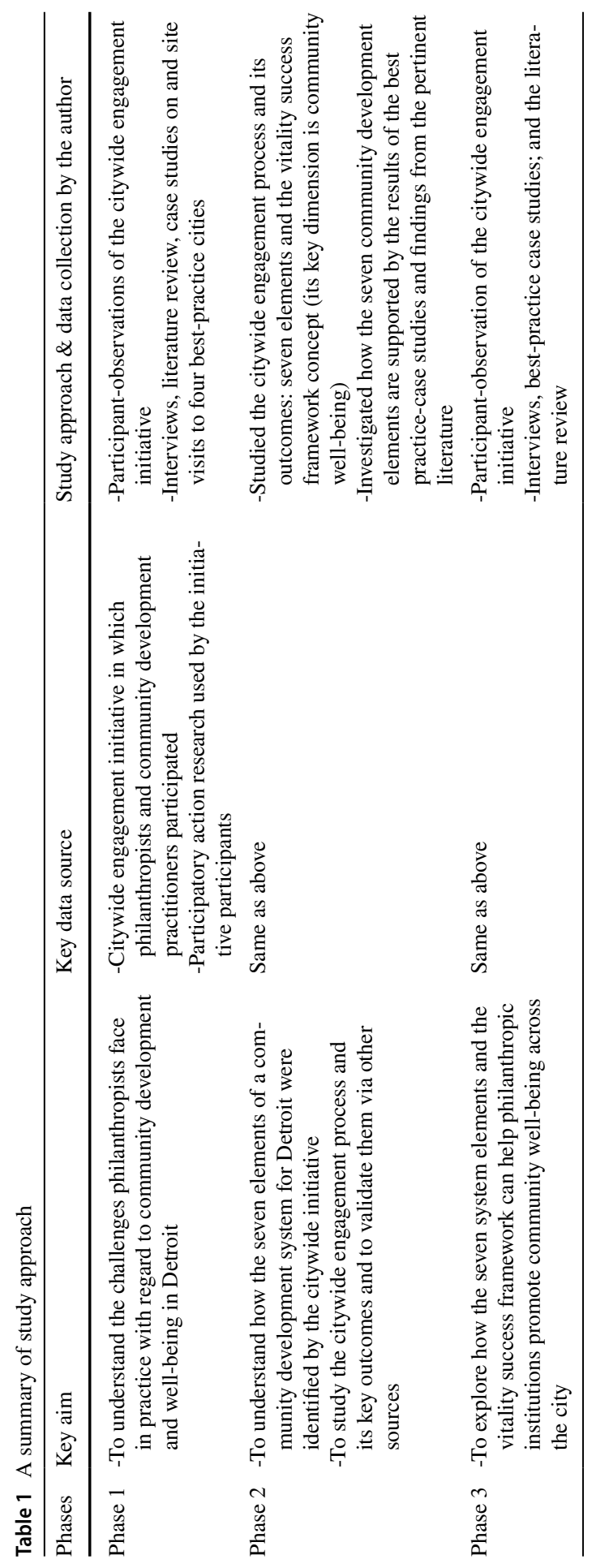


a healthy, equitable, and sustainable system for community development in Detroit. The engagement process consisted primarily of bi-weekly or monthly activities (involving kitchen cabinets, committees, task forces, and advisory boards) and annual summits. These activities took place in various locations, including nonprofit agency offices, university conference rooms, CDO meeting rooms, and the like.

\section{Phase 3}

In the third phase of the study we worked to explain how the seven system elements and the vitality success framework can help philanthropic organizations promote community well-being across the city. This phase was based on the results of the author's research efforts: participant-observation with philanthropists and other stakeholders who participated in the initiative, the best-practice case studies mentioned above, interviews, and the literature review.

\section{The Role of the Author}

The author participated in the abovementioned citywide engagement activities from 2016 to 2019 as one of the key players representing higher learning institutions in Detroit. The author also played the role of a participant-observer and researcher observing the processes in which various task forces, committees, kitchen cabinets, advisory boards, and annual summits engaged. During the participant-observation process the author took extensive notes and conducted supplementary interviews with some of the key participants in the engagement initiative. The author also conducted research on key elements of community development systems via the literature review as well as case studies on and site visits to the four best-practice cities. The author led all three phases of the study. More details on the methods referenced above are provided below.

\section{Participatory Action Research}

The citywide engagement initiative in focus was not designed originally as a participatory action research (PAR) project per se. It began as an engagement initiated by a small group of community development practitioners in Detroit. During the first three years or so of the initiative, the group grew to include nearly 200 entities. Yet the nature of the activities involved with the expanded initiative is similar to those that characterize PAR. PAR is used by community groups and organizations (where many people may already know each other and/or work together), and also by groups that come together to conduct research and act on a particular issue (Kindon et al., 2007; Pain et al., 2011). PAR also includes involvement of researchers and participants working together to understand a problematic situation and change it for the better; a focus on social change that promotes democracy and challenges inequality; context-specific work, often targeting the needs of a particular group; an 
iterative cycle of research, action, and reflection; and efforts to liberate participants through greater awareness of their situation to inform action (IDS, 2021).

Several similarities between key characteristics of the citywide engagement initiative in Detroit and of PAR exist: an approach to research in communities that emphasizes participation and action; an effort to understand the world by trying to change it, collaboratively and reflectively; and an emphasis on collective inquiry and experimentation grounded in experience and social history. These attributes align well with those of PAR (Chevalier \& Buckles, 2019; Gergen, 2014). It is worth emphasizing that although the initiative was not designed originally as PAR, the initiative features many key hallmarks of PAR through the participants' "group-ups," collective efforts, and countless iterations of their work, research, and ideas. Moreover, considering that the primary objective of the initiative was to create an equitable community development system along with the community vitality framework (whose key dimension is community well-being; more details are provided later) as a common narrative for Detroit, a PAR-style approach fits the purpose of the initiative well.

Specific methods used by the participants in the citywide engagement within this PAR-based initiative include group discussion, focus groups, workshops, interviews, diagramming, videos, photography, art, surveys, mapping, collection of environmental data, computer analysis of datasets, and more. These methods, by and large, are qualitative in nature, which is appropriate for studying the participants' reflections and actions, both of which play a key role in the PAR process. Such methodological diversity is one of the positive qualities of PAR but is also challenging. To address this challenge, we used the following three methods. Together they supplement this study through data triangulation (Lietz \& Zayas, 2010).

\section{Participant-Observation}

Participant-observation is a field research technique that is often used in anthropology and sociology. In participant-observation, an investigator (the participantobserver) studies the internal structure and dynamics of a group by sharing or participating in its activities (Clark et al., 2009; Dictionary.com, 2021; Merriam-Webster, 2021). Participant-observation is especially appropriate for exploratory studies, descriptive studies, and studies aimed at generating theoretical interpretations (Jorgensen, 2015). The use of participant-observation as a research method is appropriate for this study, considering several factors: the author was a key participant in the citywide initiative for more than three years; this article is based on an exploratory and theory-building study; and the primary data source for this article is the outcomes of the citywide engagement initiative. One of the managers of the citywide initiative documented and analyzed the outcomes of the initiative. The manager was not a participant-observation researcher but a key participant in the PAR-based citywide initiative. The author used the manager's data to cross-check and analyze the data for this article. Although this is not exactly the same as what Lietz and Zayas (2010) call "observer triangulation," the author's intent was to use more than one (PAR) investigator to analyze the data. 


\section{Site Visits to and Case Studies on Four Best-Practice Cities}

As discussed above, the author was one of the key participants in the trips to the four best-practice cities. Each site visit team consisted of 15-20 key participants in the citywide initiative representing various sectors (e.g. philanthropy, community development organizations). After all trips were completed, three separate trip reports were produced (by the author, by the citywide initiative managers, and by the consultants for the citywide initiative). Following the principles of "observer triangulation" (Lietz \& Zayas, 2010), the author consulted all three reports to analyze the data.

\section{Interviews}

The author selected small samples of interviews and used them as the secondary method to complement PAR, participant observation, site visits to and case studies on, four best-practice cities as well as the literature review. The author conducted 15 interviews. Although this article includes limited interview data, to organize frequently occurring themes or patterns the author used several techniques including coding, content analysis, categorization, mapping, and iteration. Further coding was used to discover emerging themes from the interviews. The general criteria we used to determine emerging themes were drawn from key findings in the literature regarding what constitutes an equitable community development system. The same criteria were also used to analyze some of the outcomes of the citywide initiative, case studies on the four cities, and participant-observation. We used two coders. When they disagreed, the author made the final decision.

Through the use of the abovementioned four methods, we sought to increase the credibility of our qualitative research by applying research strategies such as observer triangulation, data triangulation, prolonged engagement (working with participants for nearly three years to achieve an exhaustive look at the experience), an audit trail (keeping a detailed written account of the research procedures), peer debriefing (meeting with the participants who engaged in the initiative and the best-practice case studies, to dialogue regarding their outcomes and takeaways), member-checking (including a sample of participants to corroborate the findings), thick descriptions, and reflexivity (the author's acknowledgment of how the author's active participation in the citywide initiative might influence the research) (Wu et al., 2016; Lietz \& Zayas, 2010).

As noted in previous sections, a number of philanthropic institutions operate in the same areas or address the same issues in community development, in the absence of a community development system in Detroit. This situation presents some challenges for philanthropy, city agencies, and CDOs in their efforts to promote citywide community well-being. We now turn to Phase 1 and discuss its outcomes regarding challenges facing philanthropic institutions in Detroit. 


\section{Results}

\section{Philanthropic Institutions and Their Challenges}

A number of financial or philanthropic institutions operate in Detroit. Although they interact or collaborate with one another, each institution focuses primarily on particular types of programs or projects, targeting particular communities. It is understandable that each institution may decide to support grant proposals that match the institution's program philosophy, priority, or focus.

For example, the Erb Foundation supports green infrastructure programs in certain priority areas in Detroit, while the Skillman Foundation has been a longstanding supporter of youth education programs for a wide range of Detroit communities. Many other foundations focus on art (the Knight Foundation), economic development (the Hudson-Webber Foundation), and community engagement (the Ford Foundation). These physical, social, and economic-focused projects all aim to address various dimensions of community well-being (Rela et al., 2020).

While this practice brings some benefits, it also poses challenges, as we shall see in the comments made by philanthropists and participants in the aforementioned citywide engagement initiative. We now highlight some of the challenges that are particularly relevant to this article.

\section{Lack of Coordination in Gathering and Sharing Data}

Increasingly, program managers in philanthropic agencies in Detroit have expressed concern over a lack of coordination with financial institutions. For example, some neighborhoods have received similar types of grant support from more than one philanthropic institution on multiple occasions, while many other communities receive no grant funds at all. This reflects mainly a lack of coordinated data-gathering among and sharing between philanthropic institutions and other groups. One program manager stated:

We [local philanthropic institutions] do meet often but we don't yet have comprehensive and up-to-date data that help us identify specific needs of neighborhoods in Detroit. With the absence of such data, it is difficult to understand which communities would require funding urgently, which communities need more help than others, which communities are left behind, especially those in down market areas, how to avoid overlaps among grant funds from different agencies so that we can prioritize our funding awards in a more equitable, effective and efficient manner.

Efforts to gather, share, and update data need to be coordinated between financial institutions and can make it easier for them to promote equity in distributing grant awards across the city. Equity, or equitable community development, has been a frequent topic of discussion throughout the citywide engagement process. Participants acknowledge growing displacement and disparity between hot real estate markets/ 
gentrified areas and down-market communities in Detroit, as is common in many other large American cities (Mallach, 2018).

\section{Lack of a Coordinated Community Development System}

Although some individual sectors or organizations are doing good work in community development in Detroit, the city lacks a coordinated city-wide community development system. This causes a number of problems, particularly with reference to coordinating funding decisions across philanthropic institutions. For example, one of the key sectors in community development in Detroit is youth education and the creation of a career pipeline in community development, while another key sector focuses on capacity-building for CDOs. Both sectors need significant funding support. Some CDOs engage in youth education and also receive funding for both youth education and capacity-building. A program manager of a philanthropic institution commented that:

Our program supports groups that focus on youth education and future workforce development in community development. There are some financial institutions who offer funding for capacity-building for community development organizations. Some of these CDOs also engage in youth education and even though capacity-building and the youth education and career pipeline... each requires different expertise and skillsets. Since the city does not have a citywide community development system and system governance, it is difficult to investigate whether there is any meaningful relationship between capacitybuilding and youth education and work-force development programs. Also it is difficult to understand whether CDOs are overstretching or lacking a clear focus. These types of information would help financial institutions to prioritize or provide funding support more effectively and equitably across the city.

Such a community development system and system governance could make it easier for philanthropic institutions to coordinate their efforts across the city and avoid unnecessary or excessive overlaps in giving out grant awards repeatedly to the same CDOs. City offices (alone or in collaboration with philanthropic institutions) face similar challenges when they must decide which communities will receive which city services or grant awards (Green \& Haines, 2015; Minkler \& Wallerstein, 2012; Molden et al., 2017; Moulaert et al., 2010), although a city government may be in a better position than a financial institution to make such distribution decisions.

\section{Lack of a Common Narrative}

The cities that the author, along with other participants in the initiative, visited as case studies have developed common citywide narratives for community development, such as quality of life in Indianapolis, Indiana; and neighborhood progress in Cleveland, Ohio (Author, 2017; Initiative Consultants, 2017a; Initiative Managers, 2017). A common or shared narrative informs a common vision for community development shared by its key actors in various sectors in each city. A common narrative would make it easier for local practitioners, city officials, philanthropists, 
and other stakeholders in various sectors to communicate or discuss matters that are relevant to community development. Detroit does not have a common narrative like those in the four best-practice cities we visited. A program manager in a philanthropic institution observed:

If everyone understands a common narrative of or a shared vision for community development in their city, its key actors and stakeholders will have a similar overall expectation or a similar reference point. It can be easier for them to coordinate their effort in community development citywide. A lack of a common narrative can make it difficult for us to compare our ideas, understand similarities and differences in our practices or assess the efficacy or validity of individual goals or approaches. It can be difficult to coordinate a concerted effort across the city when we don't have a shared vision for community development in our city. In the absence of a common narrative, philanthropic institutions may not be able to effectively assess progress made by a community development organization or philanthropic institution, where the city stands in terms of community development, and whether it is going in the right direction or not.

It takes a citywide effort to develop a common narrative and a citywide engagement process in which representatives of all sectors, including philanthropy, that are essential to successful community development, participate (Boddy et al., 2004; Wilson, 2019; Zautra et al., 2008). Good examples of such citywide efforts exist in our case-study cities (Cleveland, Philadelphia, and Indianapolis) and common narratives for some of the communities in those cities are based primarily on quality of life or community well-being in a broad sense (Author, 2017; Initiative Consultants, 2017a; Initiative Managers, 2017). A common narrative is essential to a community development system, responding to a unique context in a given city. Thus, it is important for each city to marshal a citywide effort to lead a collaborative process in defining community well-being and developing its own common narrative (Kravetz, 2017; Lee et al., 2014; Palmer, 2020).

The challenges or deficiencies that Detroit faces have culminated in a call for developing a citywide community development system. This call has also come from Detroit financial institution roundtables in recent years and also from CDO leaders. In the following two sections, we introduce the participants, explain the process, and share the results of the citywide engagement initiative to develop elements of a healthy, equitable, and sustainable community development system in Detroit.

\section{Citywide Engagement Initiative and Case Studies}

This section focuses on the process, scope, and purposes of the initiative as well as the case studies (see the next section for their outcomes). Beginning in 2016, nearly 200 key players or stakeholders representing various sectors that are directly related or impacting community development participated in a citywide engagement process to develop a healthy, equitable, and sustainable community development system in Detroit. These players represent various organizations including, but not limited 
to, CDCs or other development organizations, grassroots organizations, financial institutions such as philanthropic institutions, city and state municipal offices, universities, civic organizations, and other fiduciary and non-profit agencies.

In this section we describe the process and focus of the engagement. We also explain the case studies and site visits to the four-best practice cities as part of the engagement.

\section{Process, Activities}

The citywide engagement initiative was launched in 2016 by a core group of leaders representing the community development industry, higher-learning institutions, and the non-profit sector in Detroit. This group emphasizes that the process aspect of this citywide engagement initiative is the most critical and is owned by all engagement participants collectively. Therefore, the core group does not publicize itself as the entity that is leading the engagement process.

The engagement consisted of activities involving various kitchen cabinets, committees, task forces, and advisory boards, each of which focused on particular aspects or potentially key elements of a healthy, equitable, and sustainable community development system. The groups drilled down on topics that included defining community development, its governance, its purposes, and those whom it serves; sustainable capitalization; democratization of data and evaluation of community progress and success; capacity-building for CDOs and grassroots development organizations; engagement with city governments and communities; and developing future leaders for community development.

These groups (i.e. committees, task forces, and advisory boards) met biweekly or monthly through 2019 to identify key elements of an effective community development system in Detroit. Moreover, representatives of all groups met regularly to coordinate all the teams' tasks, scopes of work, goals, and progress. The initiative also organized an annual summit beginning in 2017 that was held in every year of the initiative (including 2020 via Zoom). The summit offers a more formal venue that allows all groups to compare their work. More importantly, the summit is a special occasion where nearly 300 people in community development in Detroit come together to discuss and evaluate the initiative's ongoing work and progress and decide what to include next on its agenda. Moreover, the summit provides opportunities for formal social interaction through which shared narratives in community development are debated or decided.

\section{Case Studies}

The author traveled with the site-visit teams that visited four cities-Cleveland, Indianapolis, Philadelphia, and Boston-in 2017. These cities were recommended by some of the key leaders of the citywide engagement initiative and others who had worked in community development in those cities; they were selected for a number of reasons. Among the more important reasons was that each of the four cities has formed a mature community development system; the African American population in each city is a priority group and is the largest segment in Detroit; and these cities are also known to 
have put key elements of community development in place according to initial findings reported in the literature (Molden et al., 2017). Each of these cities has also created a common narrative (with an emphasis on the quality of life or community well-being) that is essential to its community development system (Author, 2017; Initiative Consultants, 2017a; Initiative Managers, 2017).

The trips provided direct opportunities for us to learn about each city's community development system, to gauge its effectiveness, and identify key elements. The primary goal of the trips and case studies was to crosscheck and validate the seven elements of a community development system that emerged from the citywide engagement initiative in Detroit. Each visit team consisted of 15-20 key players representing various sectors in community development, such as CDOs, City of Detroit offices, universities, nonprofits, and philanthropic institutions. The visit to each city took two days and involved day-long focus-group sessions with representatives of various sectors in community development in each host city.

After each site visit, the visit team compiled notes and conducted surveys on visit team members' lessons learned from each trip. Also, a post-visit survey was conducted with each host city's focus group. Finally, the author, the initiative managers, and the consultants for the initiative in Detroit each wrote a separate trip report and compared each other's reports. This was our attempt to increase the credibility of our qualitative research by applying research strategies such as observer triangulation, peer debriefing, and member checking (Wu et al., 2016; Lietz \& Zayas, 2010).

In the following section we summarize the key outcomes of the citywide engagement initiative, which have benefited by considering the results of the four case studies. The key outcomes (i.e. the seven system elements) provide the primary source material for this article and will be used in the rest of the article to connect community development, philanthropy, and community well-being as a common narrative (i.e. the neighborhood vitality framework concept whose primary dimension is community well-being); this established the connection for understanding how the seven system elements and common narrative can be used to help philanthropy more effectively promote community well-being citywide.

\section{Results of the Citywide Engagement Initiative}

\section{Seven System Elements}

The citywide engagement resulted in the identification of the following seven elements of a healthy, equitable, and sustainable community development system in Detroit. This section focuses on defining each element as proposed by the key participants in the engagement via a consensus-building process (see Table 2). In the section that follows we describe how their seven elements compare with what the author found in the pertinent literature. 
Table 2 A summary of the seven elements

\section{Seven elements}

Element One (system governance):

Equal partners keeping the system strong for all neighborhoods

Element Two (system capitalization):

Resources for the entire system to thrive in our neighborhoods

Element Three (data and evaluation):

Measuring progress toward vital neighborhoods

Element Four (city engagement):

City government joining forces with neighborhood-based organizations
Description

1. A structured and functioning public-private governance system comprised of representative community development stakeholders/leaders as equal partners; such a system collaboratively shepherds the entire system, designing new initiatives and advocating for community development as an important strategy for Detroit neighborhoods

2. A structured and functioning coordination and oversight system with community development stakeholders as equal partners; collaboratively shepherding all the components of the system and assuring they are aligned

1. A strategy for assuring the availability of public-private system resources for community development work, including operating support for CDOs, capacity-building for CDOs and grassroots organizations, access to shared organizational services, data and evaluation services, and low-cost debt and grant capital for community development projects

2. A long-term strategy to assure sustainable, equitable public, private, and legislated resources for community development work in Detroit

1. Accessible neighborhood-level data, research on best community development practices, and an evaluation system, all geared toward the achievement of consensus-based Neighborhood Success Measures (i.e. the Neighborhood Vitality Success Framework)

2. An agreed-on framework to define neighborhood success, with neighborhood-level data, and an "index" system to measure progress

1. City government support for community development through the recognition of certified CDOs for each City Council District, the provision of Community Development Block Grant (CDBG) support, and ongoing partnerships with CDOs to help realize the city's Master Plan

2. City government support for community development through the recognition of CDOs as critical partners, the provision of city funding for the work, and ongoing partnerships with CDOs to help fulfill the city's master plan and other neighborhood plans 
Table 2 (continued)

\begin{tabular}{ll}
\hline Seven elements & Description \\
\hline $\begin{array}{l}\text { Element Five (organizational capacity-building } \\
\text { and certification): }\end{array}$ & $\begin{array}{l}\text { 1. Systematic access to training, technical assis- } \\
\text { tance, coaching, peer support, and development } \\
\text { Effective, sustainable neighborhood-based organi- } \\
\text { of CDOs as "conveners/facilitators" in every } \\
\text { neighborhood. Help grassroots organizations play } \\
\text { an important role within a corresponding system } \\
\text { to improve CDO effectiveness by developing }\end{array}$ \\
CDO performance standards and validating CDOs \\
as conveners while helping CDOs/other organiza- \\
tions perform the identified critical community \\
development roles in every neighborhood \\
2. Systematic access to training, technical assis- \\
tance, coaching, and peer learning to support \\
CDOs and Grass Roots Organizations in playing \\
their roles in every neighborhood. CDO perfor- \\
mance standards and support to maintain high \\
performance. Capacity support to intermediaries \\
to assure effective delivery of capacity building \\
services
\end{tabular}

Element Six (neighborhood \& advocacy voice):

Citywide process and structure to articulate and advocate neighborhood priorities from the ground up

Element Seven (education \& career pipeline):

Creating an equitable and professional community development pipeline of leaders
1. A system for building cross-sector relationships and trust within every neighborhood, and then leveraging those relationships to create an influential city-wide neighborhood voice for Detroit

2. A system to build cross-sector relationships and trust within every neighborhood through "Neighborhood Action" tables, technical support for those tables, and then citywide coordination of those tables to create an influential citywide neighborhood voice

1. A number of easily accessible academic/credentialing tracks and academic "placements," starting in middle/high school, for aspiring and current community development practitioners to pursue in generating a robust pipeline of practitioners, especially people of color, from Detroit

2. A number of project-based programs and easily accessible education tracks, fellowships, and placements, for youth ages 11-24, resident leaders and aspiring and current community development practitioners; to generate a robust pipeline of community development practitioners and leaders of all ages, especially those of color from the Detroit region

1 - 2017 descriptions; 2 - 2021 descriptions (source: the citywide engagement initiative in Detroit, 2021)

\section{Vitality Framework}

As a key effort in support of Element Three, the participants in the citywide engagement initiative proposed neighborhood vitality as an overall framework within which to measure neighborhood progress and success. The initiative group worked with its paid consultants to develop the Neighborhood Vitality 
framework. The consultants wrote a report on the framework and their recommendation included suggested indicators to measure neighborhood vitality (Initiative Consultants, 2017b). The consensus among the participants is that they prefer defining vitality more broadly to include quality of life (focusing on life satisfaction), well-being (focusing on emotional, psychological, and mental health), sustainability and health (emphasizing the physical health of the built environment, neighborhoods, and residents), and sense of community (building a sense of belonging, bonding, and forming social ties). Although the specific indicators for these dimensions have not yet been finalized, these dimensions identified by the participants in the initiative are similar to those associated with community well-being (Rela et al., 2020). Through the PAR process, the participants decided that neighborhood vitality is more appropriate for Detroit's context while simultaneously addressing the well-being of the community within a broad framework of neighborhood vitality (Initiative Consultants, 2017a, b). To create an equitable and sustainable community development system for any city-and Detroit is no exception in this regard-key stakeholders must articulate a common narrative, whether it focuses on quality of life, health, or community well-being (Kravetz, 2017; Lee et al., 2014).

According to our case-study reports (Author, 2017; Initiative Consultants, 2017a; Initiative Managers, 2017), while there were many differences across the four cities we visited for our case studies, a common theme that we found running through all four is that they all have put in place a number of basic elements to promote a successful community development system (Green \& Haines, 2015; Minkler \& Wallerstein, 2012; Molden et al., 2017; Moulaert et al., 2010; Phillips et al., 2014). Those elements are similar or comparable to the seven elements that came out of the citywide engagement initiative in Detroit.

Although each city may use its own terminology (e.g. "neighborhood data and evaluation," "neighborhood success framework," or "neighborhood progress measures") or some elements may be combined (e.g. city engagement and system capitalization), elements shared by all four cities are similar, in large part, to the seven system elements of community development in Detroit (Author, 2017; Initiative Consultants, 2017a, b; Initiative Managers, 2017). Moreover, articulating a shared narrative for community development in those cities focuses on quality of life or community well-being in a broad sense and both concepts support the vitality framework in Detroit. These concepts intersect with many aspects of community development (Lee \& Kim, 2015).

A common lesson shared between the outcomes of the citywide initiative in Detroit and those of the case studies in the four cities we visited is that each of those cities had a citywide governing entity (e.g. community development trade associations in Philadelphia and Boston) that oversees a community development system and system capitalization, which helps in coordinating the efforts of all key stakeholders including philanthropic institutions (Author, 2017; Initiative Consultants, 2017a, b; Initiative Managers, 2017).

Can the abovementioned key outcomes of the citywide engagement in Detroit be validated or supported by the findings of the relevant literature? We explore this question in the following section. 


\section{Literature Support for the Seven System Elements and Common Narrative}

\section{Seven System Elements}

The purpose of this section is to increase the credibility of this research through strategies such as data triangulation (using interdisciplinary literature) and, to a lesser degree, number-checking (using members of the knowledge community, i.e. community development professionals who participated in the initiative) to corroborate the findings of the initiative and bridge theory and practice.

The seven system elements proposed by the citywide engagement initiative, when they are defined broadly, receive general support from the interdisciplinary literature. While only limited aspects of recent community development systems in Cleveland, Boston, Indianapolis, and Philadelphia have been reported in peerreviewed scholarly articles, our site visits to those cities and our literature review, taken in aggregate, seem to validate the importance or necessity of the proposed elements.

Element 1 (system governance): The literature stresses the need for an intermediary that promotes city-wide system governance for community development. Being an active part of such a system provides legitimacy to CDOs. Legitimacy develops from a combination of interpersonal relationships, shared development narratives (for example, the shared narrative in community development in Indianapolis), and the achievement of demonstrable practical outcomes (Molden et al., 2017).

Element 2 (system capitalization): Some articles report on Cleveland's city-wide and public-private partnerships in capitalization and the creative use of Community Development Block Grant (CDBG) funds. Such an approach has been recommended by various sources, although Cleveland's success is not yet fully validated in the literature. The literature suggests that diverse and dependable sources of organizational funding are among the most consistent characteristics of successful organizations (Bratt \& Rohe, 2005; Rohe \& Bratt, 2003; Walker \& McCarthy, 2010). The literature also suggests that signs of government investment create a domino effect on adjacent properties as owners of adjacent tracts gain confidence in the future of a neighborhood and begin repairing and improving their properties (Pooley, 2014).

Element 3 (data and evaluation): The literature stresses that community approval of indicators is a key to success in the data-evaluation process. Other communitybased approaches, such as setting neighborhood boundaries that make logical sense to community organizations (as opposed to using census tracts, for example), and overlaying economic data such as the unemployment rate, etc., are likely to encourage a community to form a sense of ownership of community progress assessment and actively participate in the evaluation process (Parenteau et al., 2008). All of this, as the literature suggests, should be done with open and committed sharing of data by city government (e.g. that of Milwaukee), even when they know it has the potential to be used to challenge its own policies (Ghose, 2003). Regarding organizational assessment, the risks of diversifying into service areas beyond traditional expertise can lead to failed ventures, which can create distrust and further lack of financial support. Being honest with support communities about financial issues is also cited in the literature as a key to organizational success (Bratt \& Rohe, 2005). 
Element 4 (city engagement): The literature recommends moving beyond the "thin" relationships that exist between many CDOs and their local governments and moving to a more robust form of collaboration. Greater collaboration can be established through open communication and trust and by agreeing on a planned strategy to create a "comprehensive and strategic" approach (Rich et al., 2001). Such successful partnerships, according to research, have improved service delivery, increased citizen satisfaction, and fostered greater trust in government. The literature also reports that city officials have felt most accountable to their citizens in cities with higher levels of citizen attendance at CDBG and budget hearings (Handley \& Howell-Moroney, 2010).

Element 5 (organizational capacity-building and certification): A recent article reports that CDOs, grassroots organizations, and other nonprofit organizations are likely to play an important role in reducing violence and building stronger communities (Sharkey et al., 2017). To support their role, as the relevant literature suggests in general, more work needs to be done to build capacity in these organizations. The literature generally supports the idea that capacity-building includes building member capacity, organizational capacity, programmatic capacity, relational capacity, resource capacity, and catalytic capacity (Glickman \& Servon, 2003). Other sources suggest capacity-building as a function of both a focus on skills, resources, and problem-solving abilities and participation by individual community members in a process of relationship-building, community planning, decision-making, and action (Chaskin, 2001; Jones, 2019). A recurring theme is that collaboration with other organizations (whether directly, as in co-managing an initiative; or indirectly, as in guidance and mentorship, or social, as in exchanging ideas), is a key factor in capacity-building success (Chaskin, 2001; Carman \& Fredericks, 2010; Glickman \& Servon, 1998). To build collaborative capacity and catalytic capacity, both of which maximize collective impact, various types of "learning networks" have been suggested in the literature (Carman \& Fredericks, 2010). Other sources report a lack of communication and distrust between organizations as reasons for organizational failure or downsizing at a high rate (Dewar et al., 2012; Thomson \& Etienne, 2017).

Element 6 (neighborhood voice): There is wide support from the literature for the proposition that developing a broad coalition and building consensus among members is important to achieving goals established by any cross-sector initiatives or partnerships (Bonds et al., 2015; Hutson, 2013). To establish legitimacy, it is important for organizations to gain support from residents from the start and to deliver on promises so as to establish legitimacy and develop trust within the community (Bonds et al., 2015). Some authors assert that using (social media) networks produces the best results when trying to build community, strengthen social capital, access multiple perspectives, build and share knowledge and best practices, and mobilize people and resources around a given issue (Scearce et al., 2010).

Element 7 (career pipeline): It remains challenging to inspire practitioners or staff working in the community development industry, reflecting a number of issues (e.g. lack of sustainable funding) associated with many of the elements discussed above. Instead of delving deeply into specific examples of pipelines in the literature, discussing a number of principles underlying effective educational programs in the literature is more useful to the purposes of this article. The literature 
recommends instilling programmatic flexibility, being open to multiple strategies, and remaining attentive to what works best. Some studies argue that it is essential to communicate the value of training to staff members, to provide incentives to encourage them to engage in training, to connect the context of the training with the content provided, to communicate accurate goals and objectives to allow staff to select the training that best helps them, and to integrate training with organizational capacity-building to assure that, as staff turns over; these efforts contribute to keeping a human-capacity system in place (Pitcoff, 2004).

The literature stresses the value of engaging in peer learning, peer exchange, coaching, and workshops away from a practitioner's home organization, using other models that build on each other. Other sources suggest that lessons learned from training need to be specific enough so that staff can apply them immediately; but broad enough so they can be used again, implying that the best training is about frameworks that can be used in many situations, rather than about focusing on the nitty-gritty details regarding everything (Pitcoff, 2004). This type of framework seems to provide approaches or techniques that help communitydevelopment practitioners respond with agility to complex and diverse situations, many of which are unpredictable (Wilson, 2019).

It is more challenging, however, to inspire young people to consider community development as a career choice. While there remains a perception that community development is not a well-defined industry, some entities such as universities offer programs or engage in initiatives that help to cultivate a workforce for community development or to train leaders of future generations in collaboration with CDOs (Brennan et al., 2007).

Similarly, community organizing groups that have built coalitions for local change have involved youth over the past few decades, engaging them as leaders in efforts to improve community well-being or the quality of life in their communities (Christens \& Dolan, 2011). Christens and Dolan report that this type of youth organizing model effectively produces impacts at multiple levels because the model weaves youth engagement, community development, and social change into a unified (and therefore predictable) organizing cycle. The impacts that this model promotes include empowerment, leadership, and socio-political development and those impacts are directly relevant to dimensions of community wellbeing (Rela et al., 2020). This model produces various community-level impacts, new program implementation, policy change, institution-building, and social change effected through such means as intergenerational and multicultural collaboration in the exercise of collective power in pursuit of the common good and social justice (Iwasaki, 2016). This dynamic interplay between youth development, community development, and social change allows youth to engage in social innovation that influences community development (Moulaert et al., 2010). The efforts of those organizations mentioned above illustrate how various types of programs, initiatives, or training approaches can build capacity in existing and future community development leaders. We also recognize that such efforts would require partnerships and collaboration between groups in various sectors on a longer term-basis. 


\section{Common Narrative}

A common narrative is essential to promoting community development across the city in an equitable and sustainable manner (Wheeler et al., 2014). Creating a common narrative in that regard requires community engagement involving key stakeholders, CDOs, philanthropists, and other supporting agencies (Bryson et al., 2015). These are among the lessons we learned from the case studies of the four best-practice cities.

Informed by those lessons, initiative participants in Detroit worked with the consultants to create a shared narrative for communities in Detroit. Together, they devised the neighborhood vitality framework concept. According to the consultants' report (Initiative Consultants, 2017b), the framework includes several dimensions, after considering case-study outcomes and interviews with local stakeholders (governments, philanthropic institutions, community development organizations, and others) that the consultants conducted. Those dimensions include community well-being, quality of life, health, sense of community, and sustainability.

The group debated well-being, quality of life, and vitality extensively, but eventually decided to use vitality as an overarching concept and acknowledged that community well-being is a major part of the vitality framework.

A review of the literature on community vitality reveals a wide variety of conceptualizations. A positive relationship exists between community vitality and each of the following dimensions: community well-being (Mouratidis \& Poortinga, 2020; Syhlonyk \& Seasons, 2020); quality of life (Skevington \& Böhnke, 2018; Li et al., 2017; Giles-Corti et al., 2014); sustainability (Bakar et al., 2015; Li et al., 2017; Smith \& Miller, 2013; Molavi \& Jalili, 2016); health (Andazola et al., 2019; Forsyth, 2020); and sense of community (Kee \& Nam, 2016).

Community or neighborhood vitality as analyzed in the literature appears to be much broader than the other dimensions mentioned above in terms of scope or the number of dimensions or indicators (DeFilippis \& Saegert, 2013). Moreover, vitality overlaps with quality of life and community well-being in many respects (Skevington \& Böhnke, 2018; Syhlonyk \& Seasons, 2020). In that regard, the vitality framework can easily build on accomplishments in the fields of community well-being or quality of life. (Mouratidis \& Poortinga, 2020; Li et al., 2017). Community assets build the foundation of effective and sustainable community development and promote neighborhood vitality (Green \& Haines, 2015).

The vitality framework was chosen over other concepts (community well-being, quality of life) by the initiative participants primarily because vitality stands for reenergizing, rebuilding, or rejuvenation of Detroit's communities; in the minds of many participants in the initiative, vitality captures the story and spirit of Detroit, its struggle, and its resilience (Initiative Consultants, 2017b).

Taken together, the seven system elements that emerged from the citywide engagement initiative appear to be aligned well with the key elements of effective community development as suggested by the literature. Considering both lists side by side (the list of the seven elements proposed by the citywide engagement initiative on the right and the list of seven key outcomes from the literature review on the 
left), as shown in Fig. 2, we note a number of similarities as well as points of consistency and reasonable alignment between the two lists.

How do the seven system elements help philanthropic institutions promote community well-being across the city? We address this question in the following section.

\section{Seven System Elements and Philanthropy}

Above, we discuss three key challenges facing the philanthropic sector in Detroit that have been identified as hindrances to the sector's effort to coordinate more effective funding practices in ways that promote efficacy and equity in community development. We suggest that the seven system elements and the vitality framework together lay the groundwork that will enable philanthropic institutions to promote community well-being across the city.

Informed by the initiative consultants' report on the neighborhood framework (2017), the vitality framework as a measure of neighborhood success in Detroit is broadly defined to include several dimensions, including quality of life (focusing on life satisfaction) (Sirgy, 2012), well-being (focusing on psychological, mental, and emotional health) (Christens, 2012), sustainability (Dietz et al., 2009), health (emphasizing the physical health of the people and the built environment) (Forsyth, 2020), and sense of community (instilling a sense of belonging and social

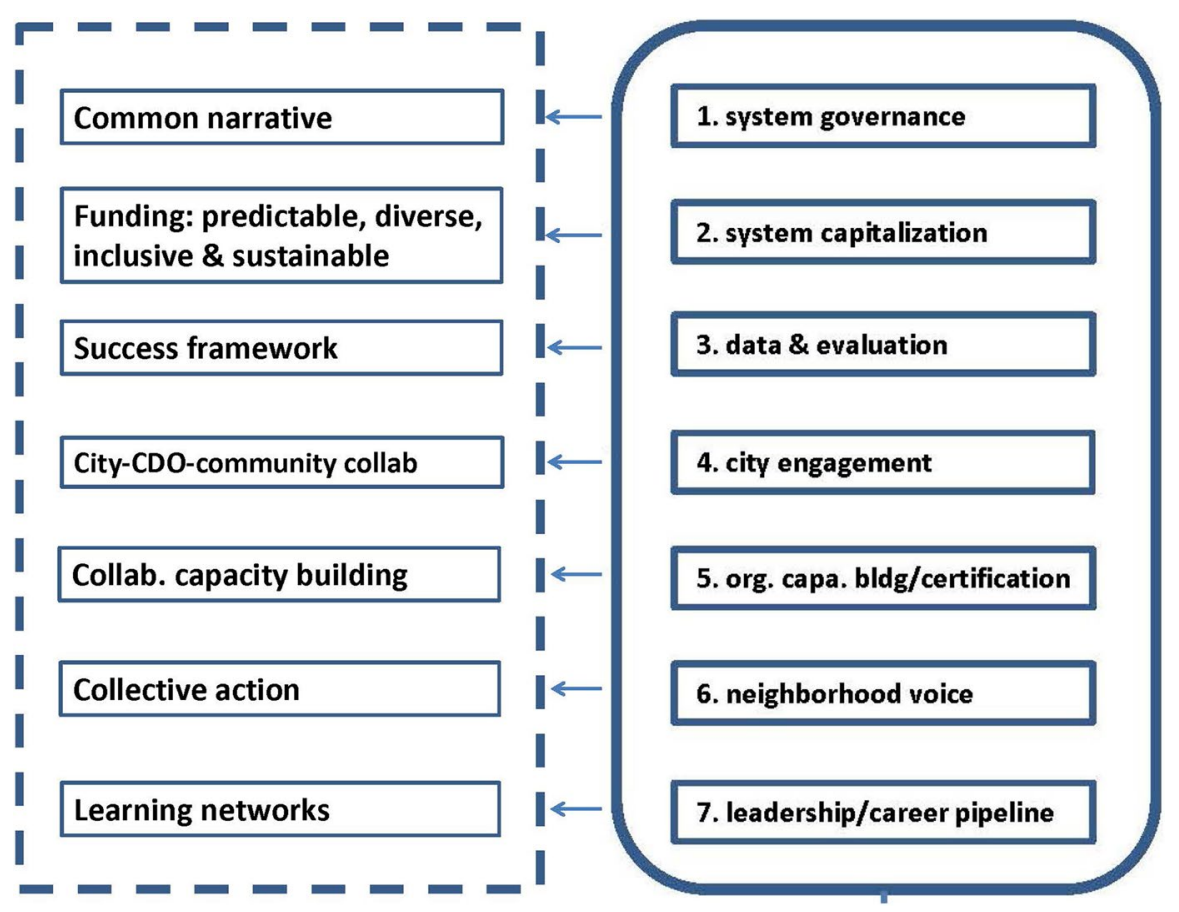

Fig. 2 Comparison of Community Development Elements: List Informed by the Literature on the Left and the Initiative List on the Right (figure created by the author) 
interaction) (Thompson \& Kent, 2014). Even though each of these dimensions has a specific focus proposed by the participants in the citywide engagement initiative, it is unrealistic for any one philanthropic institution to promote all of the dimensions successfully, or even for one community to do so, in part because every institution has a unique program focus (Farley, 2018).

In Detroit, there is a philanthropic institution that focuses on green infrastructure (the Erb Foundation), while other institutions support community-building (the Ford Foundation) or art (the Knight Foundation). Some institutions invest more intensively in healthy, equitable economic development (Hudson Webber Foundation) and other institutions are more interested in youth development (the Skillman Foundation). Green infrastructure is related to sustainability and wellbeing, two of the dimensions of the vitality success framework (Bell et al., 2014). Community-building, which is another aspect of the vitality framework, promotes sense of community (Kim, 2019). On the other hand, art promotes psychological or mental health, which is related to the well-being dimension of the vitality framework (Jensen \& Bonde, 2018). This implies that coordination and cooperation between philanthropic institutions are essential to promoting vitality or community well-being across the city (Kottke et al., 2017). This work could be better facilitated by the use of the vitality framework and the seven system elements.

Of the seven system elements, Element 3 (data and evaluation) is most directly relevant to the vitality framework and was proposed to serve as a common narrative for community development, as discussed earlier. In this regard, the framework can provide additional impetus for philanthropic institutions to be more mindful or more rigorous in promoting or meeting the expectations of the vitality framework when they render funding decisions or evaluate funding proposals or the work of CDOs.

Furthermore, many of the seven system elements can help philanthropic institutions work together to identify or determine which areas (e.g. sustainability, economic development) or communities would require a concerted effort from all or many funding agencies, which areas or communities could be better served by a group of financial institutions, or which areas or communities could be easily supported by a single philanthropic institution. Here, having reliable system governance across the city with respect to community development will provide additional resources that philanthropic institutions can use to coordinate their efforts to make equitable funding decisions across the city.

The city of Boston features a statewide, long-term community development financing system called Community Investment Tax Credits (Kriesberg, 2013), but Detroit has nothing like that. With a sustainable capitalization structure that is financed by philanthropic institutions, private corporations, and other organizations with reasonable tax credits, such a fund could be used to support programs or initiatives that may require long-term investments. This is related to Element Two (system capitalization). Having such sustainable, stable, long-term capitalization would help some philanthropic institutions focus on short-term, mid-term, or even urgent initiatives that need funds immediately. This could provide additional options for financial institutions or allow them to explore more diverse ways of promoting community well-being. 
Having a common narrative, such as the vitality success framework, supported by strategies based on Element 4 (city engagement) can help the philanthropic industry form a united voice for community well-being when negotiating with top city officials, and developing a more cooperative working relationship with these actors while having a stronger sense of direction and a common vision for community development (Braunstein \& Lavizzo-Mourey, 2011).

Currently, a number of philanthropic institutions support various CDOs in capacity-building, which is related to Element 5 (organizational capacity-building and certification). By comparison, there is a lack of funding support for Element 6 (neighborhood voice) and Element 7 (career pipeline). Neighborhood voice is related to various aspects (quality of life, well-being, sense of community) of the vitality success framework (Evans, 2008; Wilson, 2019). Career pipeline is not directly related to the vitality framework but is proposed by citywide engagement participants as a critical part of a successful community development system in Detroit. There is growing interest in engaging youth in community development and inspiring them to choose community development as a career path (Christens \& Dolan, 2011). Establishing the seven system elements in the city could help philanthropic institutions and other players understand which elements are adequately funded and which elements are neglected. Such overall understanding and clarity informed by the seven elements could also have a positive impact on philanthropic institutions' funding practices with respect to community well-being.

While the seven system elements and the vitality framework together provide a clearer sense of a common objective or vision for all concerned parties in community development, an overall picture of the lanes in which key players, including philanthropic institutions, community development organizations, and other key industry leaders, are moving forward is also needed. For example, an executive director of a well-known intermediary in Detroit commented that:

Some or even many of us [intermediaries, CDOs] often struggle to offer services in too many areas including real estate development, economic development, education, legal services, social services, youth services, capacitybuilding, etc., to increase our chance of receiving multiple grant funds from various financial institutions, and also somehow to be able to tell the communities that we can do it all. This type of situation seems to create unnecessary or unhealthy competitions among us, when in fact we should cooperate for the common good of our communities, especially when the city and we all are dealing with budget and funding cuts across the board. This practice is likely to create all kinds of conflicts and confusions among communities and organizations. This is not sustainable and not healthy. Each agency should know what its lane is and it should focus on it, and should collaborate and partner with [another] agency that is on a different lane and with a different expertise.

Similar concerns were expressed by many philanthropic institutions. For example, one philanthropic institution's program manager commented that:

If everyone shares one common objective in community development for the entire city, like Indianapolis whose common narrative is quality of life, 
it will make our funding practice more effective and make our coordination easier. When a community development organization engages in too many services, it is difficult to determine what their primary lane is and it is also difficult to evaluate their use of funding and their performance. This can be even more complicated if an organization received funds from multiple financial institutions with overlapping or similar programs.

In response, the author suggests that Detroit needs to draw an overall picture of community development as an additional way of promoting dialog between key players in distinct sectors and to complement the seven system elements and the vitality framework. Creating an overall picture will help to clarify the various development lanes, understand their relationships, coordinate various efforts more effectively, identify possible opportunities, and forge partnerships (Towe et al., 2016). Some of these ideas are included in Fig. 3, as part of this article's theory-building effort. The diagram and its supplementary explanations provided below are informed by the results of the citywide engagement initiative, the four cities case studies, and the literature review, and merit further empirical research to elaborate their implications more fully.

- The seven system elements (shown in the center of the diagram) should provide the foundation of a healthy, equitable, and sustainable community development system in Detroit, as informed by the results of the citywide engagement initiative and the literature (McConville, 2013).

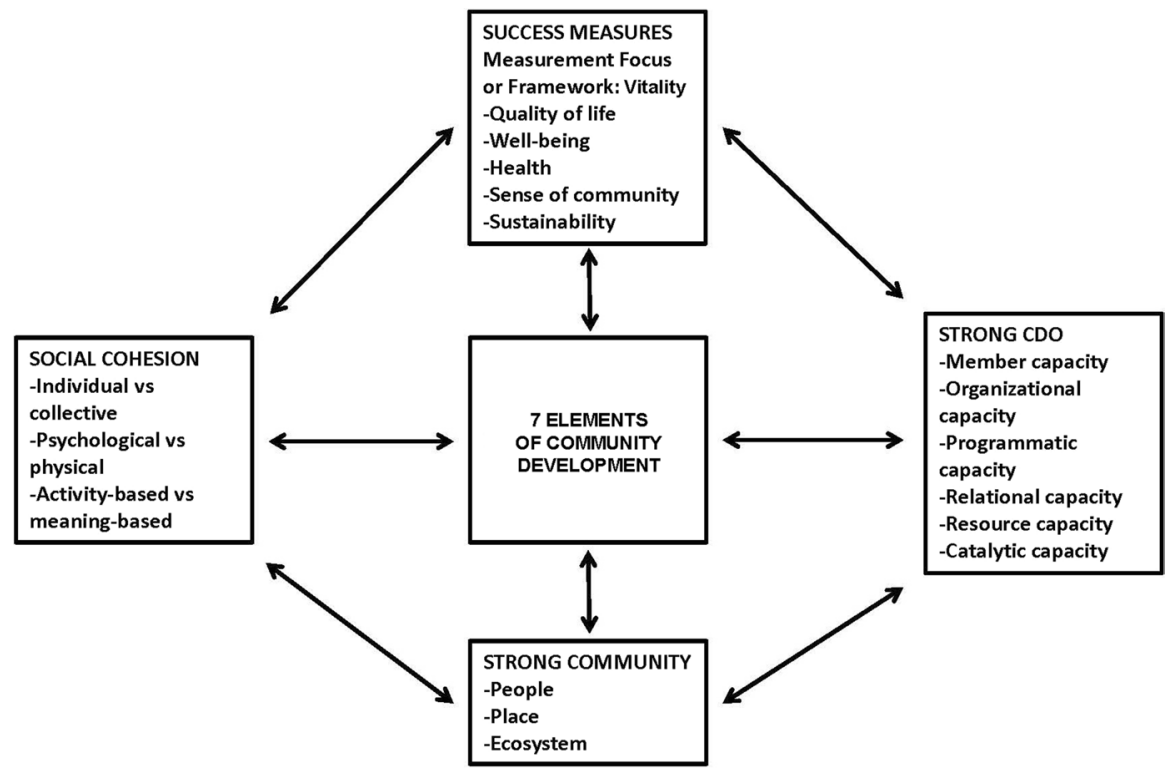

Fig. 3 Understanding the Overall Picture (figure created by the author) 
- The vitality success framework measure, bolstered by the seven system elements (especially Element 3), should be regarded and used as a common narrative for the city, as informed by the citywide engagement initiative.

- To develop a strong community, community development participants should consider people (resident engagement), place (placemaking), and the ecosystem (funding and capacity-building support) (Pineo, 2020), as informed by the results of the case studies and site visits to the four cities.

- Capacity-building for CDOs and other grassroots organizations is essential to effective community development in Detroit. CDOs are building-blocks of community development. Strong organizations are necessary to develop strong and vital communities (Green \& Haines, 2015), as informed by the results of the citywide engagement initiative and the four case studies.

- Social cohesion is essential to the vitality success framework and also to promoting strong communities, as informed by the citywide engagement initiative and by the literature review (Kim, 2020b).

In summary, the seven system elements coupled with the vitality framework, serving as a common narrative with a clear understanding of which agencies are operating in which lanes, can help philanthropic institutions conduct funding practices more effectively. The seven system elements and the common narrative can also help philanthropic institutions coordinate their efforts to promote citywide wellbeing with a stronger sense of direction towards a common vision for community development in Detroit.

\section{Study Implications and Concluding Remarks}

This theory-building article investigated how best to help philanthropic institutions address community well-being citywide and more effectively in Detroit. To address that inquiry, this study used a model that conceptualizes the use of elements of a community development system that can help better coordinate philanthropic efforts to enhance community well-being citywide. This article used the results of a citywide engagement initiative led by key players representing various sectors that have a direct impact on community development in Detroit. The author, as one of the key participants in that process, used participant-observation, scholarly literature, case studies of four best-practice cities, and interviews to corroborate the results of the engagement - the seven elements of community development.

The results of the research and the initiative suggest that system governance, system capitalization, data and evaluation, city engagement, capacity-building, neighborhood voice, and career pipelines are essential to an effective community development system in Detroit. Furthermore, these seven elements are basic conditions that should be met to help philanthropic institutions coordinate their funding practices more effectively so that community well-being is achieved citywide via the vitality success measures. This finding may be unsurprising given that community well-being dimensions, philanthropic service provision, and community development services are all quite diverse and complex (Lee et al., 2014; Rela et al., 2020), 
thereby requiring a system that helps coordinate the efforts of many actors more successfully (Harrow \& Jung, 2016).

The outcomes of this study suggest that the seven system elements are necessary (but not sufficient) conditions to be met for philanthropy to promote community well-being in a more citywide, collaborative, systematic, and equitable manner. Among the issues that need to be addressed are these: integrating objective wellbeing (e.g. focus on material well-being; objectively observable outcome measures) and subjective well-being (focus on relationships, values, norms, and behavioral outcome measures); aligning short-term and longer-term initiatives in community development (Edwards, 2011; Sung \& Phillips, 2018); supporting grassroots organizations (essential building blocks of community rebuilding and community engagement), many of which are mom-and-pop operations in serious need of capacitybuilding (Jones, 2019). These factors could have an impact on the effectiveness of philanthropic coordination.

An important takeaway from this practice-based research, also echoed in the community well-being literature (Cox et al., 2010; Wilson, 2019), is that developing success measures for community well-being is best grounded on local knowledge and local effort, to be led by local stakeholders and to be driven by community engagement; the associated process and outcomes should be shared truthfully and readily by all participants, concerned parties, and citizens. The definitions and the scope of community well-being available in the literature should be challenged, narrowed, or expanded by local stakeholders. These lessons are also informed by the literature. For example, community well-being may focus primarily on health (Palmer, 2020) and the private sector can play a significant role in community well-being (Rela et al., 2020), while social cohesion is a key driver of improved community well-being (Cramm et al., 2013; Kim, 2020a, b). Such variability encourages local stakeholders to carefully assess similarities and differences between community well-being and community development and to consider an alignment that is more suitable, sustainable, or appropriate for the unique local context (Kravetz, 2017).

The author's position, the methods used for this research, and its findings reveal both limitations and merits of this study. The author's unique role as a participantobserver of, and also as one of the players in, the citywide engagement initiative as well as his role as a researcher comparing the outcomes of the initiative and those in the scholarly literature and case studies, allowed the author to appreciate and share the value and benefits of using a bottom-up engagement initiative led by local practitioners and stakeholders instead of being led by government agencies. Such groundup efforts are vital to social change, potentially laying the groundwork for inclusive community development (Chetkovich \& Kunreuther, 2006). This bottom-up process made it possible to bring in rich and diverse perspectives on how to make community development in Detroit more equitable, sustainable, and healthier, thereby making funding practices, the vitality success framework, and community well-being measures more effective and better coordinated across the city.

Considering factors such as the scale of the citywide initiative (e.g. the large number of participants and the length of the initiative), the participant-observation led by the author, and the qualitative nature of both processes and outcomes, there is, clearly, room for potential biases in data analysis and interpretation. While using 
more coders could help, the author tried to enhance the credibility of the qualitative research by using research strategies such as data triangulation and several other techniques suggested by Lietz and Zayas (2010).

This study can be further reinforced in the following ways, which can also be regarded as topics for future research. While this study is generally based on theorybuilding, empirical research studies are necessary to validate the proposed seven system elements and to promote philanthropy in collaboration with CDOs and city governments to implement the elements in practice.

The seven system elements and the vitality success framework for community wellbeing proposed by the participants in the citywide engagement initiative have not yet been implemented in Detroit. Prior to implementation, there is a need for pilot projects to test the efficacy of the proposed community well-being framework or indicators, considering some of the distinctions associated with the use of community well-being indicators in the real world. These distinctions include individual versus community well-being, input versus output indicators, and indicators focusing on the community at large versus indicators focusing on vulnerable segments (Sirgy, 2018). The author had originally planned to conduct structured interviews with the leaders of philanthropic institutions to understand how they feel about the system elements and the vitality framework, in particular whether they feel confident that the proposed measures resulting from the citywide engagement initiative can make their funding practices more effective and make it easier for them to coordinate their efforts so that they can promote citywide community well-being more successfully. This phase did not take place because of the COVID-19 pandemic but we plan to conduct it in the near future.

Another study that is currently being planned with local partners will examine the results of implemented green infrastructure and placemaking projects funded by philanthropic institutions and determine whether the projects have contributed to increasing community well-being. This study is designed to investigate whether the benefits of such projects, if there are any, can be scaled across the entire city, if the seven system elements are implemented. While we know from the literature that green infrastructure has health benefits, more research is needed to validate the positive correlation between green infrastructure and community well-being at the city level (Bakar et al., 2015; Cox et al., 2010; Diener et al., 2009).

Both of the abovementioned studies could help us validate the outcomes of the theory-building research presented in this article. Those studies may also help us determine how to implement the seven system elements and the vitality framework more effectively across the city by building on empirical research outcomes.

This theory-building study is conceptual in nature and its outcomes cannot be generalized to apply to other cities. Nevertheless, the grassroots and holistic nature of the engagement and research could offer some useful lessons for cities facing similar challenges.

Acknowledgments The author is grateful for being part of the citywide engagement in Detroit. The author thanks anonymous reviewers for providing thoughtful comments and feedback on the draft manuscript.

\section{Declarations}

Conflict of Interest Statement The author states that there are no conflicts of interest. 


\section{References}

Andazola, J., Andrews, C., Davis, M., deMaría, J., Dillon, K., Edwards, A., \& Yonke, N. (2019). Wellbeing as a multidimensional concept: Understanding connections among culture, community, and health. Rowman \& Littlefield.

Author (2017). Findings from case studies on four best-practice cities' community development systems (for the citywide engagement initiative in Detroit). Unpublished report.

Bakar, A. A., Osman, M. M., Bachok, S., Ibrahim, M., \& Mohamed, M. Z. (2015). Modelling economic wellbeing and social wellbeing for sustainability: A theoretical concept. Procedia Environmental Sciences, 28, 286-296.

Bell, S. L., Phoenix, C., Lovell, R., \& Wheeler, B. W. (2014). Green space, health and wellbeing: Making space for individual agency. Health \& Place, 30, 287-292.

Bhattacharyya, J. (2004). Theorizing community development. Community Development, 34, 5-34.

Boddy, M., Bassett, K., French, S., Griffiths, R., Lambert, C., Leyshon, A. \& Thrift, N. (2004). Competitiveness and cohesion in a prosperous city-region: the case of Bristol. City matters. In M. Boddy, \& M. Parkinson (Eds.), Competitiveness, cohesion and urban governance, 51-70. Policy Press.

Bonds, A., Kenny, J. T., \& Wolfe, R. N. (2015). Neighborhood revitalization without the local: Race, nonprofit governance, and community development. Urban Geography, 36(7), 1064-1082.

Bradshaw, T. K. (2000). Complex community development projects: Collaboration, comprehensive programs, and community coalitions in complex society. Community Development Journal, 35(2), $133-145$.

Bratt, R. G., \& Rohe, W. M. (2005). Challenges and dilemmas facing community development corporations in the United States. Community Development Journal, 42(1), 63-78.

Braunstein, S., \& Lavizzo-Mourey, R. (2011). How the health and community development sectors are combining forces to improve health and well-being. Health Affairs, 30(11), 2042-2051.

Braverman, M. T., Constantine, N. A., \& Slater, J. K. (Eds.). (2004). Foundations and evaluation: Contexts and practices for effective philanthropy. Wiley.

Brennan, M. A., Barnett, R. V., \& Baugh, E. (2007). Youth involvement in community development: Implications and possibilities for extension. Journal of Extension, 45(4), 203-213.

Bryson, J. M., Crosby, B. C., \& Bloomberg, L. (Eds.). (2015). Creating public value in practice: Advancing the common good in a multi-sector, shared-power, no-one-wholly-in-charge world (Vol. 194). CRC Press.

Carman, J. G., \& Fredericks, K. A. (2010). Evaluation capacity and nonprofit organizations: Is the glass half-empty or half-full? American Journal of Evaluation, 31(1), 84-104.

Chaskin, R. J. (2001). Building community capacity: A definitional framework and case studies from a comprehensive community initiative. Urban Affairs Review, 36(3), 291-323.

Chetkovich, C. A., \& Kunreuther, F. (2006). From the ground up: Grassroots organizations making social change. Cornell University Press.

Chevalier, J. M., \& Buckles, D. J. (2019). Participatory action research: Theory and methods for engaged inquiry. Routledge.

Christens, B. D. (2012). Targeting empowerment in community development: A community psychology approach to enhancing local power and well-being. Community Development Journal, 47(4), 538-554.

Christens, B. D., \& Dolan, T. (2011). Interweaving youth development, community development, and social change through youth organizing. Youth \& Society, 43(2), 528-548.

Citywide engagement initiative in Detroit (2021). Updated seven elements of an equitable community development system in Detroit. Unpublished report.

Clark, A., Holland, C., Katz, J., \& Peace, S. (2009). Learning to see: Lessons from a participatory observation research project in public spaces. International Journal of Social Research Methodology, 12(4), 345-360.

Cox, D., Frere, M., West, S., \& Wiseman, J. (2010). Developing and using local community wellbeing indicators: Learning from the experience of Community Indicators Victoria. Australian Journal of Social Issues, 45(1), 71-88.

Cramm, J. M., Van Dijk, H. M., \& Nieboer, A. P. (2013). The importance of neighborhood social cohesion and social capital for the well being of older adults in the community. The Gerontologist, 53(1), 142-152.

DeFilippis, J., \& Saegert, S. (2013). The community development reader. Routledge. 
Dewar, M., \& Thomas, J. M. (Eds.). (2012). The city after abandonment. University of Pennsylvania Press.

Dictionary.Com (2021). Retrieved March 1, 2021, from https://www.dictionary.com/browse/participantobservation.

Diener, E., Lucas, R., Schimmack, U., \& Helliwell, J. (2009). Well-Being for public policy. Oxford University Press.

Dietz, T., Rosa, E. A., \& York, R. (2009). Environmentally efficient well-being: Rethinking sustainability as the relationship between human well-being and environmental impacts. Human Ecology Review, $114-123$.

Dolan, P. (2008). Social support, social justice, and social capital: A tentative theoretical triad for community development. Community Development, 39, 112-119.

Edwards, M. (2011). The role and limitations of philanthropy. The Bellagio Initiative (The future of philanthropy and development in the pursuit of human wellbeing), Institute of Development Studies, the Resource Alliance and the Rockefeller Foundation. Demos.

Evans, M. (2008). Who is for community participation? Who is community participation for? Exploring the well-being potential for involvement in regeneration. Education, Knowledge \& Economy, 2(3), $163-173$.

Farley, K. E. W. (2018). Shifting notions of philanthropy: Themes in scholarship and practice. PS, Political Science \& Politics, 51(1), 48.

Foell, A., \& Pitzer, K. A. (2020). Geographically targeted place-based community development interventions: A systematic review and examination of studies' methodological rigor. Housing Policy Debate, 30(5), 741-765.

Forsyth, A. (2020). What is a healthy place? Models for cities and neighbourhoods. Journal of Urban Design, 25(2), 186-202.

Frey, B. S. (2008). Happiness: A revolution in economics. MIT Press.

Gergen, K. J. (2014). Pursuing excellence in qualitative inquiry. Qualitative Psychology, 1(1), 49.

Ghose, R. (2003). Community participation, spatial knowledge production, and GIS use in inner-city revitalization. Journal of Urban Technology, 10(1), 39-60.

Giles-Corti, B., Macaulay, G., Middleton, N., Boruff, B., Bull, F., Butterworth, I., ... \& Christian, H. (2014). Developing a research and practice tool to measure walkability: A demonstration project. Health Promotion Journal of Australia, 25(3), 160-166.

Glickman, N. J., \& Servon, L. J. (1998). More than bricks and sticks: Five components of community development corporation capacity. Housing Policy Debate, 9(3), 497-539.

Glickman, N. J., \& Servon, L. J. (2003). By the numbers: Measuring community development corporations' capacity. Journal of Planning Education and Research, 22(3), 240-256.

Glückler, J., \& Ries, M. (2012). Why being there is not enough: Organized proximity in place-based philanthropy. The Service Industries Journal, 32, 515-529.

Green, G. P., \& Haines, A. (2015). Asset building \& community development. Sage publications.

Handley, D. M., \& Howell-Moroney, M. (2010). Ordering stakeholder relationships and citizen participation: Evidence from the community development block grant program. Public Administration Review, 70(4), 601-609.

Harrow, J., \& Jung, T. (2016). Philanthropy and community development: The vital signs of community foundation? Community Development Journal, 51(1), 132-152.

Healey, P. (2003). Collaborative planning in perspective. Planning Theory, 2(2), 101-123.

Hutson, M. A. (2013). Power, politics, and community development. Community Development, 44(1), 111-126.

IDS: Institute of Development Studies (2021). Participatory action research. Participation Research Cluster. Retrieved March 7, 2021, from https://www.participatorymethods.org/glossary/participat ory-action-research.

Initiative Consultants (2017a). Findings from a review of five "mature" community development Ecosystems (for the citywide engagement initiative in Detroit). Unpublished report.

Initiative Consultants (2017b). Neighborhood vitality indicators (for the citywide engagement initiative in Detroit). Unpublished report.

Initiative Managers (2017). Study trip summary: Community development systems in four cities (for the citywide engagement initiative in Detroit). Unpublished report.

Iwasaki, Y. (2016). The role of youth engagement in positive youth development and social justice youth development for high-risk, marginalised youth. International Journal of Adolescence and Youth, 21(3), 267-278. 
Jensen, A., \& Bonde, L. O. (2018). The use of arts interventions for mental health and wellbeing in health settings. Perspectives in Public Health, 138(4), 209-214.

Jones, B. (2019). Neighborhood planning: A guide for citizens and planners. Routledge.

Jorgensen, D. L. (2015). Participant observation: Emerging trends in the social and behavioral sciences. American Cancer Society, 1-15.

Kee, Y., \& Nam, C. (2016). Does sense of community matter in community well-being? In Social factors and community well-being (pp. 39-56). Springer.

Kim, J. (2019). The role of gaming in community engagement: Case study of a studio focused on societal challenges. In M. Dodig \& L. Groat (Eds.), The Routledge companion to games in architecture and urban planning (pp. 234-248). Routledge.

Kim, J. (2020a). Healthy inner-city communities: Toward an integrative framework. The Plan Journal, 5(2), $425-446$.

Kim, J. (2020b). The role of social cohesion in addressing the impact of COVID-19 on mental health within marginalized communities. Local Development \& Society, 1-12.

Kindon, S., Pain, R., \& Kesby, M. (Eds.). (2007). Participatory action research approaches and methods: Connecting people, participation and place (Vol. 22). Routledge.

Kottke, T. E., Pronk, N., Zinkel, A. R., \& Isham, G. J. (2017). Philanthropy and beyond: Creating shared value to promote well-being for individuals in their communities. The Permanente Journal, 21.

Kravetz, K. (2017). Strategies and agents of community well-being. In Teaching and learning about communities (pp.41-56). Palgrave Pivot.

Kriesberg, J. (2013). New community investment tax credit in Massachusetts. Retrieved June 19, 2017, from https://www.bostonfed.org/publications/communities-and-banking/2013/fall/new-community-inves tment-tax-credit-in-massachusetts.aspx.

Ledwith, M. (2020). Community development: A critical approach. Policy Press.

Lee, S. J., Kim, Y. (2015). Searching for the meaning of community well-being. In Community well-being and community development. Springer, 9-23. https://doi.org/10.1007/978-3-319-12421-6_2.

Lee, S. J., Kim, Y., \& Phillips, R. (Eds.). (2014). Community well-being and community development: Conceptions and applications. Springer.

Leventhal, T., Brooks-Gunn, J., \& Kamerman, S. B. (2007). Communities as place, face, and space: Provision of services to poor, urban children and their families. In J. DeFilippis \& S. Saegert (Eds.), The community development reader (pp. 109-117). Routledge.

Lietz, C. A., \& Zayas, L. E. (2010). Evaluating qualitative research for social work practitioners. Advances in Social Work, 11(2), 188-202.

Li, X., Lv, Z., Zheng, Z., Zhong, C., Hijazi, I. H., \& Cheng, S. (2017). Assessment of lively street network based on geographic information system and space syntax. Multimedia Tools and Applications, 76(17), 17801-17819.

Mallach, A. (2018). The divided city: Poverty and prosperity in urban America. Island Press.

Martinez-Cosio, M., \& Bussell, M. R. (2013). Catalysts for change: 21st century philanthropy and community development. Routledge.

Matarrita-Cascante, D., \& Brennan, M. A. (2012). Conceptualizing community development in the twentyfirst century. Community Development, 43, 293-305.

McConville, M. (2013). Creating equitable, healthy, and sustainable communities: Strategies for advancing smart growth, environmental justice, and equitable development (No. EPA 231-K-10-005).

McCrea, R., Walton, A., \& Leonard, R. (2014). A conceptual framework for investigating community wellbeing and resilience. Rural Society, 23(3), 270-282. https://doi.org/10.1080/10371656.2014.11082070

Merriam-Webster (2021). Retrieved March 1,2021, fromhttps://www.merriamwebster.com/dictionary/parti cipant\%20observation.

Minkler, M., \& Wallerstein, N. (2012). Introduction to community organizing and community building. In Community organizing and community building for health and welfare (pp. 5-26). Rutgers University Press.

Molavi, M., \& Jalili, F. (2016). Comparison of vitality between two streets of Tehran. Urbanism, Arhitectura. Constructii, 7(4), 267-284.

Molden, O., Abrams, J., Davis, E. J., \& Moseley, C. (2017). Beyond localism: The micropolitics of local legitimacy in a community-based organization. Journal of Rural Studies, 50, 60-69.

Moulaert, F., Swyngedouw, E., Martinelli, F., \& Gonzalez, S. (Eds.). (2010). Can neighbourhoods save the city?: Community development and social innovation. Routledge.

Mouratidis, K., \& Poortinga, W. (2020). Built environment, urban vitality and social cohesion: Do vibrant neighborhoods foster strong communities?. Landscape and Urban Planning, 204, 103951. 
Pain, R., Whitman, G, \& Milledge, D. (2011). Participatory action participatory action research toolkit: An introduction to using PAR as an approach to learning, research and action. Durham University \& Lune Rivers Trust. Retrieved February 1,2021, from http://communitylearningpartnership.org/wpcontent/uploads/2017/01/PARtoolkit.pdf.

Palmer, C. (2020). Fitness philanthropy and social capital: An emerging research agenda for sport and community well-being. International Journal of Community Well-Being, 1-14.

Parenteau, M. P., Sawada, M., Kristjansson, E. A., Calhoun, M., Leclair, S., Labonté, R., ... \& Herold, S. (2008). Development of neighborhoods to measure spatial indicators of health. URISA Journal, 20(2), 43-55.

Phillips, R., \& Pittman, R. (Eds.). (2014). An introduction to community development. Routledge.

Pineo, H. (2020). Towards healthy urbanism: Inclusive, equitable and sustainable (THRIVES)-an urban design and planning framework from theory to praxis. Cities \& Health, 1-19.

Pitcoff, W. (2004). Investing in people: Building the capacity of community development, training, and social enterprise practitioners. Rockefeller Foundation.

Pooley, K. B. (2014). Using community development block grant dollars to revitalize neighborhoods: The impact of program spending in Philadelphia. Housing Policy Debate, 24(1), 172-191.

Prilleltensky, I., \& Prilleltensky, O. (2007). Promoting well-being: Linking personal, organizational, and community change. Wiley.

Reich, R. (2014). Gift Giving and philanthropy in market democracy. Critical Review, 26, 408-422.

Rela, I. Z., Ramli, Z., Rusdan, M., Mappasomba, M., \& Nikoyan, A. (2020). Conceptual model of corporate social responsibility impact on community well-being. Entrepreneurship and Sustainability Issues, $8(2), 311$.

Rich, M. J., Giles, M. W., \& Stern, E. (2001). Collaborating to reduce poverty: Views from city halls and community-based organizations. Urban Affairs Review, 37(2), 184-204.

Rohe, W. M., \& Bratt, R. G. (2003). Failures, downsizings, and mergers among community development corporations. Housing Policy Debate; Abingdon 14(1,2), 1-46.

Scearce, D., Kasper, G., \& Grant, H. M. (2010). Working wikily. Stanford Social Innovation Review, 8(3), 30-37.

Sharkey, P., Torrats-Espinosa, G., \& Takyar, D. (2017). Community and the crime decline: The causal effect of local nonprofits on violent crime. American Sociological Review, 82(6), 1214-1240.

Sirgy, M. J. (2012). The psychology of quality of life: Hedonic well-being, life satisfaction, and eudaimonia (Vol. 50). Springer Science \& Business Media.

Sirgy, M. J. (2018). What types of indicators should be used to capture community well-being comprehensively? International Journal of Community Well-Being, 1(1), 3-9.

Sirgy, M. J., Widgery, R. N., Lee, D. J., \& Yu, G. B. (2010). Developing a measure of community well-being based on perceptions of impact in various life domains. Social Indicators Research, 96(2), 295-311. https://doi.org/10.1007/s11205-009-9479-9

Skevington, S. M., \& Böhnke, J. R. (2018). How is subjective well-being related to quality of life? Do we need two concepts and both measures? Social Science \& Medicine, 206, 22-30.

Smith, R., \& Miller, K. (2013). Ecocity mapping using GIS: Introducing a planning method for assessing and improving neighborhood vitality. Progress in Community Health Partnerships: Research, Education, and Action, 7(1), 95-106.

Sung, H., \& Phillips, R. G. (2018). Indicators and community well-being: Exploring a relational framework. International Journal of Community Well-Being, 1(1), 63-79.

Syhlonyk, A., \& Seasons, M. (2020). The concept and measurement of community well-being: Lessons for planners. Planning Practice \& Research, 1-16.

Thompson, S., \& Kent, J. (2014). Connecting and strengthening communities in places for health and wellbeing. Australian Planner, 51(3), 260-271.

Thomson, D. E., \& Etienne, H. (2017). Fiscal crisis and community development: The great recession, support networks, and community development corporation capacity. Housing Policy Debate, 27(1), 137-165.

Tov, W., \& Diener, E. (2009). The well-being of nations: Linking together trust, cooperation, and democracy. In The Science of well-being (pp. 155-173). Springer.

Towe, V. L., Leviton, L., Chandra, A., Sloan, J. C., Tait, M., \& Orleans, T. (2016). Cross-sector collaborations and partnerships: Essential ingredients to help shape health and well-being. Health Affairs, 35(11), 1964-1969.

Walker, E. T., \& McCarthy, J. D. (2010). Legitimacy, strategy, and resources in the survival of community-based organizations. Social Problems, 57(3), 315-340. 
Walton, A., McCrea, R., \& Leonard, R. (2014). CSIRO survey of community wellbeing and responding to change: Western Downs region in Queensland. CSIRO land and water Retrieved February 1, 2021, from http://gisera.org.au/publications/tech_reports_papers/socioeco-proj-3-communitywellbeing-report.pdf.

Wilson, P. A. (2019). The heart of community engagement: Practitioner stories from across the globe. Routledge.

Wheeler, S. M., \& Beatley, T. (Eds.). (2014). Sustainable urban development reader. Routledge.

Wu, S., Wyant, D. C., \& Fraser, M. W. (2016). Author guidelines for manuscripts reporting on qualitative research. Journal of the Society for Social Work and Research, 7(2), 405-425.

Zautra, A., Hall, J., \& Murray, K. (2008). Community development and community resilience: An integrative approach. Community Development, 39(3), 130-147.

Publisher's note Springer Nature remains neutral with regard to jurisdictional claims in published maps and institutional affiliations. 